\title{
El uso de las macrorreglas en la comprensión lectora de textos expositivos
}

\section{The use of macro-rules reading comprehension of expository texts}

\author{
Cintya Estefani Julcamayan Chagua \\ Jeancarlo Joel García Guadalupe \\ Universidad Nacional de Educación \\ Universidad Nacional de Educación \\ «Enrique Guzmán y Valle», Lima, Perú «Enrique Guzmán y Valle», Lima, Perú \\ cjulcamayan@une.edu.pe \\ jgarciag@une.edu.pe
}

\section{Resumen}

Esta investigación abordó el problema ¿cómo repercute el uso de las macrorreglas en la comprensión de textos expositivos? La población estuvo conformada por 190 estudiantes del segundo grado de secundaria de la Institución Educativa 1190 de Chosica. Se diseñaron y aplicaron un cuestionario y una prueba, empleando un diseño correlacional-causal a 18o, mediante un censo que excluyó a los estudiantes que tenían asistencia irregular. Los resultados evidencian que el uso de las macrorreglas repercute en los niveles de comprensión literal, inferencial y crítico de textos expositivos. Por lo tanto, se concluye que el uso de las macrorreglas repercute en la comprensión de textos expositivos ( $\mathrm{p}<0.01 ; \mathrm{r}=0.317$ que se considera una correlación débil y 10,1\% de influencia).

Palabras clave: uso de las macrorreglas, macrorregla de supresión, macrorregla de generalización, macrorregla de construcción, comprensión de textos expositivos.

\begin{abstract}
This research focuses on answering the question, how does the use of macro-rules affect the understanding of expository texts? The population consisted of 190 students of the second grade of secondary school from the 1190 Educational Institution in Chosica. A questionnaire and a test were designed and applied, using a correlational-causal design, to 180 students, through a census that excluded some of them who had irregular attendance. The results show that the use of macro-rules affects the levels of literal, inferential and critical understanding of expository texts. Therefore, it is concluded that the use of macro-rules affects the understanding of expository texts ( $\mathrm{p}<0.01 ; \mathrm{r}=0.317$ which is considered a weak correlation and $10.1 \%$ influence).
\end{abstract}

Keywords: use of macro-rules, deletion macro-rule, generalization macro-rule, construction macro-rule, reading comprehension of expository texts.

Recibido: 29.06.19

Aceptado: 15.08.19 


\section{Jeancarlo Joel García Guadalupe}

\section{Introducción}

El Perú tiene bajos niveles de lectura, según diversos exámenes internacionales, por ejemplo, los resultados de las pruebas del Programme for International Student Assessment (PISA), según los cuales se ubica casi siempre en los últimos lugares. A pesar de que actualmente se aprecia mejoría en los puntajes, estos no evidencian que gran parte de alumnos tenga buenos resultados. Esta situación se caracteriza porque los alumnos no emplean estrategias para los diferentes formatos y tipos textuales. Además, los alumnos tienen dificultad para hallar el tema, los subtemas, la idea principal y las ideas temáticas de textos expositivos, el hecho principal y los hechos secundarios de textos narrativos y la tesis y argumentos de textos argumentativos.

Las habilidades de lectura se clasifican en ocho escalas: debajo del nivel 1b, nivel 1b, nivel 1a, nivel 2, nivel 3, nivel 4, nivel 5 y nivel 6.

Tabla 1. Resultados del Perú en pruebas PISA de lectura 2000-2015

\begin{tabular}{l|l|l|l|l|l|l|l}
\hline PISA 2000 & \multicolumn{3}{|c|}{ PISA 2009 } & \multicolumn{3}{c}{ PISA 2012 } & \multicolumn{3}{l}{ PISA 2015 } \\
\hline $\begin{array}{l}\text { Niveles de } \\
\text { desempeño }\end{array}$ & $\%$ & $\begin{array}{l}\text { Niveles de } \\
\text { desempeño }\end{array}$ & $\%$ & $\begin{array}{l}\text { Niveles de } \\
\text { desempeño }\end{array}$ & $\%$ & $\begin{array}{l}\text { Niveles de } \\
\text { desempeño }\end{array}$ & $\%$ \\
\hline & & 6 & 0,0 & 6 & 0,0 & 6 & 0,0 \\
\hline 5 & 0,1 & 5 & 0,4 & 5 & 0,5 & 5 & 0,3 \\
\hline 4 & 4,9 & 4 & 2,6 & 4 & 3,3 & 4 & 3,5 \\
\hline 3 & 14,5 & 3 & 10,1 & 3 & 11,4 & 3 & 15,0 \\
\hline 2 & 25,5 & 2 & 22,1 & 2 & 24,9 & 2 & 27,3 \\
\hline 1 & 54,1 & $1 \mathrm{a}$ & 28,7 & $1 \mathrm{a}$ & 29,5 & $1 \mathrm{a}$ & 28,3 \\
\hline & & $1 \mathrm{~b}$ & 22,0 & $1 \mathrm{~b}$ & 20,6 & $1 \mathrm{~b}$ & 19,2 \\
\hline Promedio & 327 & Promedio & 370 & Promedio & 384 & Promedio & 398 \\
\hline
\end{tabular}

Fuente: Ministerio de Educación (2016b) y Ministerio de Educación (2017b).

Según la tabla anterior, en Perú los alumnos se ubican en 2, 1a y 1b. Entonces se aprecia que sus estudiantes, en su mayoría, no logran alcanzar niveles altos, a diferencia de los alumnos de otros países. Sin embargo, nuestro país presenta crecimiento continuo, según sus promedios de desempeño en las pruebas PISA más recientes: 
El uso de las macrorreglas en la comprensión lectora de textos expositivos

Tabla 2. Resultados de Latinoamérica en las pruebas PISA de lectura 2000-2015

\begin{tabular}{l|l|l|l|l|l|l|l} 
& $\begin{array}{l}\text { PISA } \\
\mathbf{2 0 0 0}\end{array}$ & $\begin{array}{l}\text { PISA } \\
\mathbf{2 0 0 9}\end{array}$ & $\begin{array}{l}\text { PISA } \\
\mathbf{2 0 1 2}\end{array}$ & $\begin{array}{l}\text { PISA } \\
\mathbf{2 0 1 5}\end{array}$ & $\begin{array}{l}\text { Variación } \\
\mathbf{2 0 0 9 - 2 0 1 2}\end{array}$ & $\begin{array}{l}\text { Variación } \\
\mathbf{2 0 1 2 - 2 0 1 5}\end{array}$ & $\begin{array}{l}\text { Tendencia } \\
\text { promedio }^{* *}\end{array}$ \\
\hline Perú & 327 & 370 & 384 & 398 & $+14^{\star}$ & 13 & $+14^{\star}$ \\
\hline Colombia & & 413 & 403 & 425 & -10 & $+22^{\star}$ & +6 \\
\hline Uruguay & & 426 & 411 & 437 & $-14^{\star}$ & $+25^{\star}$ & $+5^{\star}$ \\
\hline Chile & 410 & 449 & 441 & 459 & -8 & $+17^{\star}$ & +5 \\
\hline México & 422 & 425 & 424 & 423 & -2 & 0 & -1 \\
\hline Brasil & & 412 & 407 & 407 & -5 & +1 & -2 \\
\hline $\begin{array}{l}\text { Costa } \\
\text { Rica }\end{array}$ & & 443 & 441 & 427 & -2 & -13 & $-9^{\star}$ \\
\hline
\end{tabular}

${ }^{\star}$ Diferencias significativas al $5 \%$.

** La OECD (2016) estima la tendencia promedio como una ponderación de las variaciones en el tiempo de cada país. Esta depende de los ciclos en que hayan participado.

Fuente: Ministerio de Educación (2016b) que cita a la OECD (2016).

Estos resultados se pueden comparar con los resultados de la Evaluación Censal de Estudiantes (ECE) del 2015, que tiene menos cantidad de niveles o categorías en su clasificación y que se realiza cada año para los niveles de primaria y secundaria. Para esta investigación son importantes los resultados del segundo grado de educación secundaria, por ser parte de la unidad muestral:

Tabla 3. Resultados de la IE 100 en la prueba ECE de lectura 2015

\begin{tabular}{l|l|l|l|l}
\hline \multirow{2}{*}{ Niveles de logro } & IE & \multicolumn{3}{|c}{ Todo el país } \\
\cline { 3 - 5 } & & Nacional & Hombre & Mujer \\
\hline Satisfactorio & $19,6 \%$ & $14,7 \%$ & $13,9 \%$ & $15,5 \%$ \\
\hline En proceso & $34,2 \%$ & $22,6 \%$ & $22,6 \%$ & $22,7 \%$ \\
\hline En inicio & $37,0 \%$ & $39,0 \%$ & $39,5 \%$ & $38,5 \%$ \\
\hline Previo al inicio & $9,2 \%$ & $23,7 \%$ & $24,0 \%$ & $23,4 \%$ \\
\hline Total & 100,0 & $100,0 \%$ & $100,0 \%$ & $100,0 \%$ \\
\hline
\end{tabular}

Fuente: Ministerio de Educación (2016a, p. 10).

En el año 2015, el 19,6 \% de estudiantes se ubicó en Satisfactorio; el 34,2 \%, En proceso; el 37 \%, En inicio y puede extraer información explícita, deducir relaciones lógicas de causalidad, deducir el tema y reflexionar sobre aspectos formales 
del texto. Finalmente, el 9,2 \% se ubicó en Previo al inicio y no logró los aprendizajes para estar en la categoría anterior. En la ECE se presentan los resultados por secciones evaluadas, indicando el número de alumnos según su categoría:

Tabla 4. Resultados de las secciones de la IE en la prueba ECE de lectura 2015

\begin{tabular}{|c|c|c|c|c|c|}
\hline \multirow{2}{*}{ Sección } & \multicolumn{4}{|c|}{ Nivel } & \multirow{2}{*}{ Total } \\
\hline & Satisfactorio & En proceso & En inicio & Previo al inicio & \\
\hline A & 6 & 14 & 14 & 2 & 36 \\
\hline B & 9 & 14 & 12 & 3 & 38 \\
\hline $\mathrm{C}$ & 10 & 14 & 8 & 2 & 34 \\
\hline $\mathrm{D}$ & 3 & 5 & 11 & 3 & 22 \\
\hline $\mathrm{E}$ & 4 & 11 & 13 & 2 & 30 \\
\hline $\mathrm{F}$ & 4 & 5 & 10 & 5 & 24 \\
\hline Total & 36 & 63 & 68 & 17 & 184 \\
\hline
\end{tabular}

Fuente: Ministerio de Educación (2016a, p. 14).

Se aprecia que las secciones $\mathrm{B}$ y C obtuvieron mejores resultados que las demás. $\mathrm{Al}$ año siguiente, la situación nacional en la ECE 2016 fue mejor y además se puede visualizar el desempeño de la UGEL y la DRELM:

Tabla 5. Resultados nacionales, de la UGEL 06 y la DRELM en la prueba ECE de lectura 2016

\begin{tabular}{l|l|l|l}
\hline Niveles de logro & UGEL 06 Ate & DRELM & Nacional \\
\hline Satisfactorio & $22,4 \%$ & $21,9 \%$ & $14,3 \%$ \\
\hline En proceso & $35,0 \%$ & $35,5 \%$ & $27,5 \%$ \\
\hline En inicio & $34,2 \%$ & $34,0 \%$ & $37,7 \%$ \\
\hline Previo al inicio & $8,4 \%$ & $8,6 \%$ & $20,5 \%$ \\
\hline Total & $100,0 \%$ & $100,0 \%$ & $100,0 \%$ \\
\hline
\end{tabular}

Fuente: Ministerio de Educación (2017a, p. 27).

Se puede ver que los resultados de la UGEL o6 son mejores en Satisfactorio y En proceso que los resultados a nivel nacional, pero son muy similares a los resultados de la DRELM. En cuanto a los resultados a nivel nacional, son muy bajos, si se los compara con la UGel o6 los de la DRELM.

34 Lengua \& Sociedad, vol. 18, n. ${ }^{\circ}$ 1, Lima, enero-junio de 2019 
El uso de las macrorreglas en la comprensión lectora de textos expositivos

Tabla 6. Resultados de la IE 100 en la prueba ECE de lectura 2016

\begin{tabular}{l|l|l|l|l}
\hline \multirow{2}{*}{ Niveles de logro } & IE & \multicolumn{3}{|c}{ Sexo } \\
\cline { 2 - 5 } & Cantidad & Porcentaje & Hombre & Mujer \\
\hline Satisfactorio & 18 & $9,5 \%$ & 8 & 10 \\
\hline En proceso & 67 & $35,3 \%$ & 38 & 29 \\
\hline En inicio & 92 & $48,4 \%$ & 38 & 54 \\
\hline Previo al inicio & 13 & $6,8 \%$ & 7 & 6 \\
\hline Total & 190 & $100,0 \%$ & 91 & 99 \\
\hline
\end{tabular}

Fuente: Ministerio de Educación (2017a, p. 4).

Se aprecia que los resultados del colegio aumentaron en las categorías Satisfactorio y En proceso, a diferencia de las categorías En inicio y Previo al inicio que se redujeron. A continuación se presentan los resultados por sección:

Tabla 7. Resultados de las secciones de la IE en la prueba ECE de lectura 2016

\begin{tabular}{|c|c|c|c|c|c|}
\hline \multirow{2}{*}{ Sección } & \multicolumn{4}{|c|}{ Nivel } & \multirow{2}{*}{ Total } \\
\hline & Satisfactorio & En proceso & En inicio & Previo al inicio & \\
\hline A & 5 & 11 & 14 & 2 & 32 \\
\hline B & 3 & 13 & 13 & 0 & 29 \\
\hline C & 3 & 13 & 13 & 2 & 31 \\
\hline $\mathrm{D}$ & 2 & 15 & 14 & 2 & 33 \\
\hline $\mathrm{E}$ & 2 & 9 & 13 & 1 & 25 \\
\hline $\mathrm{F}$ & 2 & 3 & 11 & 3 & 19 \\
\hline G & 1 & 3 & 14 & 3 & 21 \\
\hline Total & 18 & 67 & 92 & 13 & 190 \\
\hline
\end{tabular}

Fuente: Ministerio de Educación (2017a, p. 5).

Se observa que los mejores resultados fueron conseguidos por las secciones A y B. Dos años después, la situación nacional en la prueba ECE 2018 es un poco mejor, ya que hubo incremento en las categorías Satisfactorio y En proceso (Ministerio de Educación, 2019): 


\section{Jeancarlo Joel García Guadalupe}

Tabla 8. Resultados nacionales en pruebas ECE de lectura 2015-2018

\begin{tabular}{l|l|l|l}
\hline Niveles de logro & Prueba 2015 & Prueba 2016 & Prueba 2018 \\
\hline Satisfactorio & $14,7 \%$ & $14,3 \%$ & $16,2 \%$ \\
\hline En proceso & $22,6 \%$ & $27,5 \%$ & $27,7 \%$ \\
\hline En inicio & $39,0 \%$ & $37,7 \%$ & $37,5 \%$ \\
\hline Previo al inicio & $23,7 \%$ & $20,5 \%$ & $18,5 \%$ \\
\hline Promedio & 561 & 567 & 571 \\
\hline
\end{tabular}

Fuente: Adaptación del Ministerio de Educación (2019).

También se puede apreciar que hubo una reducción en los niveles En inicio y Previo al inicio desde la ECE 2015 hasta la ECE 2018. En la ECE 2018, los resultados detallados del colegio son los siguientes:

Tabla 9. Resultados de la IE 100 en la prueba ECE de lectura 2018

\begin{tabular}{l|l|l|l|l|l}
\hline \multirow{2}{*}{$\begin{array}{l}\text { Niveles de } \\
\text { logro }\end{array}$} & \multicolumn{3}{|c|}{ Su IE } & Sexo & DRELM \\
\cline { 2 - 7 } & Cantidad & Porcentaje & Hombre & Mujer & \\
\hline Satisfactorio & 41 & $21,9 \%$ & 17 & 24 & $25,0 \%$ \\
\hline En proceso & 67 & $35,8 \%$ & 36 & 31 & $34,5 \%$ \\
\hline En inicio & 64 & $34,2 \%$ & 36 & 28 & $32,9 \%$ \\
\hline $\begin{array}{l}\text { Previo al } \\
\text { inicio }\end{array}$ & 15 & $8,0 \%$ & 7 & 8 & $7,6 \%$ \\
\hline Total & 187 & $100,0 \%$ & 96 & 91 & $100,0 \%$ \\
\hline
\end{tabular}

Fuente: Adaptación del Ministerio de Educación (2019).

Los resultados del colegio evidencian que la mayoría se ubica en las categorías Satisfactorio y En proceso, a diferencia de las categorías En inicio y Previo al inicio que tienen menores cantidades. Se resalta que los resultados de la institución educativa son inferiores a los resultados promedio de la DRELM.

36 Lengua \& Sociedad, vol. 18, n. ${ }^{\circ}$ 1, Lima, enero-junio de 2019 
El uso de las macrorreglas en la comprensión lectora de textos expositivos

Tabla 10. Resultados de las secciones de la IE en la prueba ECE de lectura 2018

\begin{tabular}{|c|c|c|c|c|c|}
\hline \multirow{2}{*}{ Sección } & \multicolumn{4}{|c|}{ Nivel } & \multirow{2}{*}{ Total } \\
\hline & Satisfactorio & En proceso & En inicio & Previo al inicio & \\
\hline A & 9 & 11 & 13 & 4 & 37 \\
\hline B & 11 & 13 & 10 & 1 & 35 \\
\hline C & 6 & 20 & 8 & 2 & 36 \\
\hline $\mathrm{D}$ & 4 & 5 & 16 & 0 & 25 \\
\hline $\mathrm{E}$ & 2 & 11 & 9 & 3 & 25 \\
\hline $\mathrm{F}$ & 9 & 7 & 8 & 5 & 29 \\
\hline Total & 41 & 67 & 64 & 15 & 187 \\
\hline
\end{tabular}

Fuente: Adaptación del Ministerio de Educación (2019).

En la tabla se observa que las mejores puntuaciones lo tienen los segundos A, B y F de secundaria. Para finalizar, en la siguiente tabla se muestra el avance del colegio en cuanto a lectura:

Tabla 11. Resultados de la IE 100 en pruebas ECE de lectura 2015-2018

\begin{tabular}{l|l|l|l}
\hline Nivel de logro & Prueba 2015 & Prueba 2016 & Prueba 2018 \\
\hline Satisfactorio & $19,6 \%$ & $9,5 \%$ & $21,9 \%$ \\
\hline En proceso & $34,2 \%$ & $35,3 \%$ & $35,8 \%$ \\
\hline En inicio & $37,0 \%$ & $48,4 \%$ & $34,2 \%$ \\
\hline Previo al inicio & $9,2 \%$ & $6,8 \%$ & $8,0 \%$ \\
\hline Total & $100,0 \%$ & $100,0 \%$ & $100,0 \%$ \\
\hline
\end{tabular}

Fuente: Adaptado de Ministerio de Educación (2019).

A nivel del colegio, se concluye que, a lo largo de los años, el nivel de comprensión aumentó en los niveles Satisfactorio y En proceso, pero se redujo en el nivel En inicio y Previo al inicio. 
Jeancarlo Joel García Guadalupe

Tabla 12. Resultados del SIMON en segundo grado de secundaria del año 2019

\begin{tabular}{l|l|l|l|l|l|l|l}
\hline \multirow{2}{*}{ Capacidad } & \multicolumn{6}{|c}{ Secciones de segundo grado de secundaria y porcentajes de aciertos } \\
\cline { 2 - 9 } & A & B & C & D & E & F & G \\
\hline $\begin{array}{l}\text { Obtiene } \\
\text { información }\end{array}$ & $57.20 \%$ & $55.19 \%$ & $64.58 \%$ & $71.88 \%$ & $72.50 \%$ & $65.28 \%$ & $42.78 \%$ \\
\hline $\begin{array}{l}\text { Infiere e interpreta } \\
\text { información }\end{array}$ & $55.08 \%$ & $51.17 \%$ & $52.29 \%$ & $63.01 \%$ & $55.83 \%$ & $58.33 \%$ & $46.85 \%$ \\
\hline Reflexiona y evalúa & $49.43 \%$ & $45.22 \%$ & $52.72 \%$ & $61.72 \%$ & $54.50 \%$ & $45.83 \%$ & $42.78 \%$ \\
\hline
\end{tabular}

Fuente: Autoría propia.

La Dirección Regional de Lima Metropolitana aplica evaluaciones de entrada y de salida en el marco del Sistema de Monitoreo y Evaluación de la Calidad del Servicio Educativo (SIMON). En estos resultados se puede apreciar que el nivel de Obtiene información, equivalente al nivel literal de comprensión de textos, es el que mejores resultados acertados tiene, en cambio el nivel Reflexiona, equivalente al nivel crítico de comprensión de textos, tiene resultados acertados bajos, más de la mitad del salón no puede contestar las preguntas pertinentes a este nivel.

Los datos expuestos demuestran que los estudiantes peruanos no obtienen resultados buenos en pruebas internacionales, pero hay puntajes regulares en pruebas de carácter nacional. Entonces se aprecia que hay mejoras recientemente, pero no son significativas y persisten los niveles bajos, a comparación de promedios deseables de desempeño. La situación del colegio es parecida a la nacional y, por consiguiente, se plantean interrogantes sobre los resultados de las pruebas de lectura ECE y SIMON. Entre estas interrogantes se pueden mencionar las siguientes: ¿Cómo repercute el uso de las macrorreglas en la comprensión de textos expositivos de los estudiantes del segundo grado de secundaria? ¿Cómo repercute el uso de las macrorreglas en el nivel de comprensión literal de textos expositivos? ¿Cómo repercute el uso de las macrorreglas en el nivel de comprensión inferencial de textos expositivos? ¿Cómo repercute el uso de las macrorreglas en el nivel de comprensión crítica de textos expositivos? De la misma manera, la hipótesis de trabajo afirma que el uso de las macrorreglas repercute en la comprensión de textos expositivos de los estudiantes del segundo grado de secundaria. El objetivo de esta investigación es explicar la repercusión del uso de las macrorreglas en la comprensión de textos expositivos de los estudiantes del segundo grado de secundaria. 


\section{Marco teórico}

\subsection{Las macrorreglas}

Van Dijk (1978) propone estrategias para la comprensión de textos dentro del marco de la lingüística textual. Estas estrategias son llamdas tradicionalmente macrorreglas, aunque, actualmente, se prefiera la denominación de macroestrategias. Estas macroestrategias tienen como propósito resumir la información semántica que está presente en un texto (Guerra y Martín, 1992) y de esa manera obtener el tema o significado global del texto o discurso.

En otras palabras, la persona que lee reduce la cantidad de información de las microestructuras para obtener la mínima cantidad de información importante representada en la macroestructura de un texto. Los cambios o transformaciones de este trance de microestructuras a macroestructuras conlleva una serie de actividades denominadas macroestrategias, que tienen como objetivo establecer lo más importante de un texto y diferenciarlo de aspectos o características irrelevantes. Además, estas macroestrategias no se emplearán en un orden estricto y de la misma manera, porque esto depende del tipo de texto y género textual: «el tipo de discurso determina la aplicación de las macrorreglas» (Vela, 2017, p. 22).

Estas macrorreglas, denominadas posteriormente por Van Dijk (1978) estrategias macroestructurales por ser operaciones cognitivas más flexibles (Guerra y Martín, 1992), se organizan en operaciones mentales de elisión o anulación (omisión y selección) y sustitución (generalización y construcción) (Van Dijk, 1978, Guerra y Martín, 1992, Atencio, 2014 y Pallares, 2016):
(1) $(\mathrm{a}, \mathrm{b}, \mathrm{c})=\mathrm{b}$
1. Omitir
2. Seleccionar
(2) $(a, b, c)=d$
3. Generalizar
4. Construir

Según Solé (1999), las macrorreglas propuestas por Van Dijk (1983) son similares a las propuestas por Brown, Campione y Day (1981). La propuesta de Van Dijk (1983), mencionada por Solé (1999) para resumir un texto, establece cuatro: omitir, seleccionar, generalizar y construir o integrar.

Las estrategias macroestructurales constituyen un grupo de tácticas cognitivas que permiten realizar determinadas selecciones eficaces que tengan como consecuencia la adecuada interpretación del discurso (Atencio, 2014 y Van Dijk y Kintsch, 1983). 
La aplicación de las macrorreglas permite elaborar el resumen de un texto. El resumen de un texto y el texto original del cual se deriva el resumen se asemejan en cuanto a su estructura (Málaga, 2013 y Atencio, 2014).

\subsection{Tipos de macrorreglas}

En esta investigación se considera la siguiente distribución de macrorreglas:

Tabla 13. Tipos de macrorreglas

\begin{tabular}{l|l}
\hline Criterio 1 & Criterio 2 \\
\hline Supresión u omisión & Supresión \\
\hline Selección & Generalización \\
\hline Generalización & Construcción \\
\hline Construcción &
\end{tabular}

Fuente: Autoría propia.

\subsubsection{Supresión u omisión}

Se prescinde de la información trivial, innecesaria e irrelevante de un texto para comprender el resto de la información que sí se considera importante. Esta macroestrategia opera cuando la idea principal está expresa literalmente en el texto, ya sea al inicio, en medio al final del párrafo (Pallares, 2016).

Los criterios para suprimir la información pueden ser:

- Características casuales, no inherentes, de los conceptos (Guerra y Martín, 1992).

- Las que no sean proposiciones de las subsiguientes proposiciones de la secuencia, es decir, omitir proposiciones que carecen de una «función» anterior o posterior para el texto (Málaga, 2013 y Vela, 2017).

- Detalles (Vela, 2017; Atencio, 2014).

- Ejemplos (Atencio, 2014).

- Repeticiones (Atencio, 2014).

Es importante recordar que Atencio (2014) afirma que no es posible omitir una proposición cuando hace de presuposición para otra proposición del mismo macronivel, porque ya no sería completamente interpretable.

En esta investigación se considera la macrorregla de selección dentro de la supresión. La selección de información se basa en la identificación de la oración 
temática (oración que representa la macroestructura de un párrafo o texto) (Guerra y Martín, 1992). Las proposiciones que permiten la interpretación de otras proposiciones están incluidas en la macroestructura y, por ende, son importantes. Atencio (2014) menciona que esta macrorregla es reversible porque hay la posibilidad de reconstruir la información omitida mediante procesos lógicos.

Se selecciona la información según distintos criterios:

- Se elige la proposición que le dé sentido a todo el texto (Pallares, 2016).

- Se optar por las proposiciones que contengan palabras que sean repetidas o referidas en todo el texto.

Solé (1999, p. 128) propone el ejemplo: «Laura bajó a la playa y tendió su toalla amarilla en la arena. Entró en el agua y se bañó». Después de omitir y seleccionar, solo quedaría «Laura bajó a playa y se bañó».

Díaz-Barriga y Hernández (2003, p. 296) proponen el siguiente ejemplo (el subrayado indica la selección):

El ciclo del agua en la naturaleza

El agua que existe en la naturaleza, distribuida en mares, ríos, manantiales y lagos, puede cambiar de estado por la acción de diversos factores del medio, y así pasar del estado gaseoso al líquido o al sólido en una serie de transformaciones que forman un ciclo.

Málaga (2013) y Atencio (2014) proponen una serie de proposiciones a manera de ejemplo que se han adaptado: i) Pasó un gato, ii) Colgaba en su cuello un cascabel y iii) El cascabel era dorado. Luego, se deduce que lo más importante era «Un gato pasó». Otro ejemplo: i) El mochilero se fue a la estación, ii) Pidió un boleto, iii) Pagó el boleto, iv) Subió al bus y v) Se fue a Carabayllo. Finalmente, se concluye que lo más importante es «El mochilero subió al bus y se fue a Carabayllo».

Se suprime la información innecesaria y no cambia el significado del texto. Por otro lado, se selecciona la información importante. Estas operaciones mentales trabajan a nivel literal, es decir, se realiza con información explícita. La evidencia o producto de la supresión es el subrayado, es decir, al subrayar hemos eliminado de forma mental la información irrelevante y solo subraya mos la información importante.

En textos narrativos se seleccionan personajes y acciones relacionados al problema o nudo y, a veces como en las historietas, los diálogos que luego son reforzados por la narración. Por otro lado, se suprimen los seres vivos que solo son mencionados, las descripciones detalladas y diálogos relacionados a hechos 


\section{Jeancarlo Joel García Guadalupe}

secundarios. En las fábulas se debe poner atención a la moraleja. En los mitos se debe encontrar el origen de algo. En las leyendas se debe hallar las explicaciones fantásticas de que algo existe. En la anécdota se debe encontrar lo gracioso o sorpresivo.

En textos expositivos se seleccionan palabras clave (sustantivos, adjetivos y verbos) que se relacionan con todo el texto y no solo con un párrafo. Estas palabras clave se repiten constantemente, se reemplazan por sinónimos o hiperónimos y se les hace referencia. Se suprimen los datos repetidos, imprecisos, los ejemplos, las comparaciones, las fechas, las cifras, las citas o lo que dice un personaje en un texto expositivo, las explicaciones (entre comas, paréntesis o rayas) y las descripciones detalladas.

En textos argumentativos se seleccionan las opiniones o posturas a favor o en contra, los ejemplos, los datos que sustentan las opiniones o posturas y las citas en las que haya opiniones de expertos, las comparaciones. Se suprimen fechas, detalles, explicaciones (entre comas, paréntesis o rayas) y las descripciones detalladas.

\subsubsection{Generalización}

Esta macroestrategia pretende obtener «superconceptos» que se derivan de los conceptos de las proposiciones del texto (Vela, 2017), formulando así oraciones temáticas o tópicos. Estos conceptos generales no deben seleccionarse arbitrariamente, ni muy generales (debe ser mínima), sino de la información seleccionada del texto. Este proceso también denominado abstracción (Guerra y Martín, 1992) utiliza hiperónimos para abarcar los hipónimos presentes en el texto.

Solé (1999, p. 128) propone el siguiente ejemplo: «Entró en la cocina y vio encima de la mesa cerezas, fresas, manzanas, melocotones...», se puede reemplazar los elementos por el hiperónimo fruta. Así solo quedaría: «Entró a la cocina y vio encima de la mesa frutas».

Díaz-Barriga y Hernández (2003, p. 296) presentan el siguiente ejemplo del texto «El ciclo del agua en la naturaleza»: se mencionan los estados «gaseoso», «líquido» y «sólido», los que pueden reemplazarse por un «concepto supraordinado» como «estados de la materia».

Málaga (2013) y Atencio (2014) establece una serie de proposiciones a manera de ejemplo que se han adaptado: i) En el piso estaba el trompo, ii) En el piso estaban el carrito de madera y la aplanadora iii) En el piso estaban rieles de trenecitos. Luego se generaliza y resulta la siguiente proposición: «En el piso estaban los juguetes». 
Se generalizan o reemplazan grupos de palabras por una palabra o grupo que los abarquen o engloben. Esta operación mental trabaja a nivel inferencial, es decir, se realiza con información implícita. En un texto expositivo, las palabras abarcadas (denominadas hipónimos) pueden ser sustantivos o nombres, verbos y adjetivos y la palabra que las englobe debe tener la misma categoría gramatical (y se constituiría en un hiperónimo). En un texto narrativo, los términos englobados son sustantivos o verbos. La evidencia o producto de la generalización es el parafraseado, es decir, escribir con nuestras propias palabras (sustantivos, adjetivos y verbos) lo más importante del texto. Si se realiza la escritura en los márgenes de cada párrafo, entonces estamos elaborando el sumillado.

\subsubsection{Construcción}

La macroestrategia de construcción rehace una proposición (en la forma es nueva) que abarque la información implícita del texto. La información que es reconstruida tiene como base el conocimiento y las experiencias del lector. Esta lector debe procesar la información nueva del texto en forma de serie de conceptos relacionados (condiciones habituales, circunstancias, secuencias y consecuencias de una situación o proceso) (Guerra y Martín, 1992 y Atencio, 2014). Según estos autores, la diferencia con la generalización reside en que esta última se basa en la relación de cada elemento sustituido con el sustituto y, en cambio, la construcción presenta la relación de los elementos sustituidos en conjunto (Guerra y Martín, 1992) o como totalidad (Vela, 2017) con el sustituto.

Solé (1999, p. 128) propone el ejemplo:

Por fin llegó el último día de julio. Ordenó los papeles del despacho, cerró cuidadosamente las ventanas y comprobó que desconectaba las luces. Ocupó el resto de la tarde en preparar las maletas y cerrar la casa. Al atardecer, subió en el coche, y condujo durante un par de horas hasta la costa. Al día siguiente, tomó el primer baño de mar antes de desayunar.

Al aplicar la construcción o integración, se puede llegar a la proposición «Salió de viaje por vacaciones».

Díaz-Barriga y Hernández (2003, p. 296) proponen el siguiente ejemplo del texto «El ciclo del agua en la naturaleza» cuyos párrafos, del tercero al sexto, mencionan las fases del ciclo del agua, que puede construirse así: «Las distintas fases del ciclo del agua son manifestaciones de cambios de un estado a otro de la materia». 
Málaga (2013) y Atencio (2014) establecen una serie de proposiciones a manera de ejemplo que se han adaptado: i) Fui a la estación, ii) Compré un boleto, iii) Me dirigí al paradero, iv) Subí al bus y v) El bus inició su partida. Luego se construye la siguiente proposición: «Subí al bus».

En resumen, en la aplicación de esta macroestrategia se reemplazan proposiciones del texto por otro que solamente menciona lo más importante, ya que denota su conclusión o consecuencia. Esta operación mental trabaja a nivel inferencial, es decir, se realiza con información implícita. En un texto narrativo, las acciones se reemplazan por enunciados que expresen lo mismo con otras palabras. La evidencia o producto de la construcción es el parafraseado, esto es, escribir con nuestras propias palabras (sustantivos, adjetivos y verbos) lo más importante del texto. Si se realiza la escritura en los márgenes de cada párrafo, entonces estamos elaborando el sumillado.

La macrorregla de construcción es más propicia para los textos narrativos.

\subsection{La microestructura y la macroestructura}

La microestructura hace referencia a un nivel local del texto o discurso. La microestructura es parte de la estructura de las proposiciones individuales (llamadas ideas por Pallares en el año 2016) y las relaciones lineales (Málaga, 2013 y Atencio, 2014) existentes entre estas: coherencia lineal. Descubrir la microestructura, mediante la búsqueda de la estructura más pequeña en la conformación del texto, es la primera operación mental que se hace al comprender un texto. Cada proposición está formada por un tópico y comentario, denominados también como tema y rema, es decir, la información ya conocida y la información nueva. A este proceso de desarrollar la información, de convertir la nueva en ya conocida y que se relacionen entre sí, se denomina progresión temática (Pallares, 2016).

Alexopoulou (2011, párr. 13) afirma que «a nivel oracional el texto estructura sus elementos a través de la microestructura (o planos de organización textual) que corresponde a la coherencia semántica entre las oraciones». Para Alliende y Condemarín (1998), la microestructura o estrato opera a nivel literal y corepercute con las letras, palabras, oraciones y párrafos de un texto. Además, esta microestructura sirve de base para construir la macroestructura o intertexto. Van Dijk (1978) emplea continuamente el término «secuencia» para dar cuenta de las oraciones relacionadas entre sí (que tienen coherencia local), más adelante denominadas «microestructuras».

44 Lengua \& Sociedad, vol. 18, n. ${ }^{\circ}$ 1, Lima, enero-junio de 2019 
Golder y Gaonacíh $(2002,2005)$ sostienen que la microestructura textual corresponde a una representación literal y está formada por una red jerarquizada de proposiciones que describen «la significación local, literal del texto» (p. 130). Estas proposiciones están jerarquizadas según la repetición y tienen la forma: predicado (Argumento 1, Argumento 2). En esta definición de proposición, el argumento es de lo que se habla y el predicado califica un argumento o la relación existente entre varios argumentos (Golder y Gaonacíh, 2005).

Teniendo en cuenta las consideraciones anteriores, se presentan los siguientes ejemplos:

A los griegos les gustaba el arte. Cuando los romanos conquistaron a los griegos, les copiaron, y así aprendieron a crear arte bello» (Golder y Gaonacíh, 2002, p. 130). Se aprecia la existencia de ocho microproposiciones existentes: «1. Gustar (griegos, arte), 2. Bello (arte), 3. Conquistar (romanos, griegos), 4. Copiar (romanos, griegos), 5. (Cuando 3, 4), 6. Aprender (romanos, 8), 7. Consecuencia $(3,6)$ y 8 crear (romanos, 2) (Golder y Gaonacíh, 2002, p. 130).

El vino Riesling acompaña estupendamente los crustáceos, y combina de manera ideal con la tradicional col agria» (Golder y Gaonacíh, 2005, p. 81). Se aprecian cinco microproposiciones en el texto: «1. Acompaña (Riesling, crustáceos), 2. Estupendamente (1), 3. Combina con (Riesling, col agria), 4. De manera ideal (3) y 5. Tradicional (col agria) (Golder y Gaonacíh, 2005, p. 81).

En los ejemplos anteriores se puede apreciar que las proposiciones tienen predicados en la forma de verbo, adjetivo o adverbio y que las proposiciones se pueden utilizar como argumentos en otras proposiciones evidenciando una relación de subordinanción (Golder y Gaonacíh, 2005). Estos autores reflexionan y afirman que mientras más proposiciones tenga un párrafo demandará más tiempo para comprenderlo, a diferencia del conteo y comprensión de palabras; además, «cuando un párrafo ofrece más argumentos diferentes, la legibilidad de estos sufre una disminución» (p. 81).

Por otro lado, la macroestructura está integrada por la información más global y general que caracteriza al discurso como un todo: coherencia global (Málaga, 2013). La habilidad de identificar y comprender la macroestructura implicaría actividades como identificar el tema del texto, hacer un resumen del texto o discriminar la información importante de la irrelevante (Guerra y Martín, 1992 y Málaga, 2013).

Alexopoulou (2011, párr. 12), basado en van Dijk (1980), afirma: «La macroestructura (contenido textual) se refiere a la organización global del contenido del 


\section{Jeancarlo Joel García Guadalupe}

texto y es la que garantiza la coherencia textual al vincular las oraciones entre sí». Los géneros discursivos o textuales pueden diferenciarse mediante la identificación de su macroestructura, así Alexopoulou (2011, párr. 14) afirma que la macroestructura:

Es la que nos permite procesar la información del texto y reconocer los géneros gracias a los asuntos tratados. La macroestructura de una carta comercial y la macroestructura de una carta de amor son dos ejemplos significativos.

Para Alliende y Condemarín (1998), la macroestructura o intertexto reconstruye el texto identificando su estructura global de significado o contenido y permite obtener el tema o asunto del discurso. Para obtener esta macroestructura o representación abstracta se realizan macroperaciones o macrorreglas. Van Dijk (1978) llama macroestructuras a «las conexiones [de las oraciones] que se basan en el texto como un todo» (p. 55). Estas relaciones se enmarcan en la coherencia global.

Golder y Gaonacíh (2002, 2005) manifiestan que la macroestructura textual es la representación global del texto y está constituida por proposiciones (macroproposiciones) vinculadas entre sí y jerarquizadas que no tienen sentido literal (a excepción de proposiciones o microproposiciones que puede adoptar la forma y el sentido de una macroproposición) y resumen la red microestructural mediante la aplicación de macrorreglas. Golder y Gaonacíh (2002) expresan que las macrorreglas «consisten en suprimir o en organizar ciertas microproposiciones (supresión de los elementos de detalles o resumen de varias microproposiciones en una sola), o también en elaborar proposiciones más complejas» (p. 131). Por ejemplo, en las siguientes oraciones se aprecian microproposiciones y la macroproposición que los interpreta:

- Luis fue al paradero, adquirió un boleto, y se dirigió al bus (microproposiciones).

- Luis sale de viaje en bus (macroproposición)

- El Pinot Gris, ese vino opulento de una gran nobleza, es llamado también Tokay (microproposiciones).

- El Pinot Gris es llamado también Tokay (macroproposición).

- El Gewurztraminer, el Riesling, el Sylvaner y el Pinot Gris solo se comercializan en botella (microproposiciones).

- Los «Alsacia» solo se comercializan en botella (macroproposición).

46 Lengua \& Sociedad, vol. 18, n. ${ }^{\circ}$ 1, Lima, enero-junio de 2019 
Entonces, para Golder y Gaonacíh (2002) «la elaboración de la macroestructura se desprende la mayor parte de las veces de la interpretación y de la construcción de la microestructura» (p. 31).

Cuando se leen, las proposiciones que conforman la microestructura también están elaborando la macroestructura. En esta macroestructura se consideran el conocimiento y las inferencias, ya que es una especie de resumen mental del texto que elabora el lector para su comprensión. (Guerra y Martín, 1992; Araoz, Guerrero, Villaseñor y Galindo, 2008). Identificar la macroestructura de un texto tiene las siguientes funciones (Pallares, 2016):

- Dar coherencia global a las oraciones de un párrafo.

- Discriminar el grado relevancia de una idea respecto de otra, es decir, individualizar la información.

- Reducir partes extensas de información en un número menor de ideas comprensibles sin que se pierda información importante.

La macroestructura tiene diferentes niveles jerárquicos, por eso hay macroestructura del texto completo, de un capítulo o de un párrafo (Málaga, 2013). Para obtener la macroestructura a partir de la microestructura, se aplican las macrorreglas o estrategias (Pallares, 2016):

Tabla 14. Uso de estrategias para obtener la macroestructura a partir de la microestructura

\begin{tabular}{l|l|l|}
\hline $\begin{array}{l}\text { Microestructura } \\
\text { (nivel local) }\end{array}$ & Uso de estrategias $\rightarrow$ & $\begin{array}{l}\text { Macroestructura } \\
\text { (nivel global) }\end{array}$ \\
\hline $\begin{array}{l}\text { YYYYYYYYYYYYYYYYYY } \\
\text { YYYYYYYYYYYY. }\end{array}$ & Supresión & YYYYYYYY. \\
\cline { 2 - 3 } $\begin{array}{l}\text { YYYYYYYYYYYYYYYYYY } \\
\text { YYYYYYYYYYYY. }\end{array}$ & Selección & Yeneralización \\
\cline { 2 - 2 } & Construcción & \\
\hline
\end{tabular}

Fuente: Adaptado de Pallares (2016, p. 42).

La macroestructura está estrechamente relacionada con la coherencia. La coherencia es la propiedad inherente al texto que consiste en entenderlo como un todo unitario con sus partes interrelacionadas. Esta propiedad trata de mantener la cantidad y la calidad de información relacionada al tema. La macroestructura incluye el tema y los subtemas, sin importar el tipo textual. En otras palabras, todo texto, sin importar tu tipología, tiene tema y subtemas. 
El tema muestra el asunto del texto, es decir, indica de qué se trata el texto a través de los párrafos. El tema se expresa mediante una frase nominal o sintagma nominal. Cada texto tiene un solo tema (Ministerio de Educación, 2014 y 2015).

Los subtemas son los aspectos o partes del tema que se desarrollan en el texto. El subtema también se formula por medio de una frase nominal. Cada subtema puede desarrollarse en un párrafo o más, dependiendo de la extensión y la complejidad del texto. La cantidad de subtemas varía o cambia con cada texto (Ministerio de Educación, 2014 y 2015).

Tabla 15. Comparación del título, tema y subtemas

\begin{tabular}{|l|l|l|l|}
\cline { 2 - 4 } & Título & Tema & Subtemas \\
\hline Estructura & $\begin{array}{l}\text { Puede ser sintagma } \\
\text { nominal u oración. }\end{array}$ & Sintagma nominal & Sintagma nominal \\
\hline Cantidad en el texto & 1 & 1 & Varía según el texto \\
\hline Presencia del verbo & Puede tener verbo & No tiene verbo & No tiene verbo \\
\hline
\end{tabular}

Fuente: Autoría propia.

La macroestructura no es igual para todos los tipos de textos. Si bien todos tienen tema y subtemas, cada tipo de texto desarrolla estos temas de distinta manera: los textos expositivos y descriptivos presentan idea principal desarrollada mediante ideas temáticas; los textos argumentativos, tesis y argumentos; los textos narrativos, hecho principal y hechos secundarios; finalmente, los textos instructivos, regla o paso importante y reglas o procedimientos derivados.

La macroestructura de un texto expositivo incluye la idea principal y las ideas temáticas.

La idea principal es el enunciado u oración que comenta y explica un tema. Las ideas temáticas hacen referencia explícita o implícita en todo el texto a la idea principal. Cada texto tiene una sola idea principal que se expresa como una oración (Ministerio de Educación, 2014 y 2015).

Las ideas temáticas son las oraciones que explican los subtemas. Se escriben como una oración, es decir, contienen al menos un verbo. Cada idea temática puede desarrollarse en un párrafo o más, dependiendo de la extensión y complejidad del texto. La cantidad de ideas temáticas varía en cada texto (Ministerio de Educación, 2014 y 2015).

48 Lengua \& Sociedad, vol. 18, n. ${ }^{\circ}$ 1, Lima, enero-junio de 2019 
El uso de las macrorreglas en la comprensión lectora de textos expositivos

Tabla 16. Orden de identificación de la macroestrutura

\begin{tabular}{l|l}
\hline Tema & Idea principal \\
\hline Subtema 1 & Idea temática 1 \\
\hline Subtema 2 & Idea temática 2 \\
\hline Subtema 3 & Idea temática 3 \\
\hline
\end{tabular}

Fuente: Ministerio de Educación (2014 y 2015, p. 14).

Primero se identifica el tema, luego los subtemas, después las ideas temáticas y, finalmente, la idea principal. Por otro lado, el Ministerio de Educación (2013), en su texto Comprensión y producción de textos escritos vi Ciclo, menciona que primero se identifican el tema y la idea principal, después se identifican los subtemas e ideas temáticas, luego se reconoce y emplea la estructura. Finalmente, se elabora el resumen (p. 38).

Sánchez (1993) aporta al debate una serie de procesos y su relación con conceptos de lingüística textual, el marco lingüístico de la macroestructura y las macrorreglas:

Tabla 17. Procesos en la comprensión de textos y conceptos de lingüística

\begin{tabular}{l|l}
\hline Procesos & Conceptos de lingüística \\
\hline Análisis perceptivo de las señales escritas & Segmentación \\
\hline Reconocimiento de señales escritas & Categorización-combinación \\
\hline Atribución de un significado a las señales escritas & Comprensión-interpretación \\
\hline Organización de estos significados en proposiciones & Proposición \\
\hline Reconstrucción de las relaciones entre proposiciones & Microestructura \\
\hline $\begin{array}{l}\text { Extracción del significado general de una secuencia de } \\
\text { proposiciones }\end{array}$ & Macroestructura \\
\hline Asignación de las proposiciones a una categoría funcional & Superestructura \\
\hline $\begin{array}{l}\text { Construcción de un modelo de situación en el que los } \\
\text { hechos denotados tengan alguna virtualidad }\end{array}$ & $\begin{array}{l}\text { Vínculo con la vida diaria del } \\
\text { sujeto }\end{array}$ \\
\hline
\end{tabular}

Fuente: Sánchez (1993), citado por García (2014, p. 68).

\subsection{Comprensión de lectura}

Para la autora Solé (1999, p. 137) la comprensión de lectura «es un proceso de construcción de significados acerca del texto que pretendemos comprender». En esta misma línea, menciona que se debe considerar lo siguiente: 


\section{Jeancarlo Joel García Guadalupe}

- Antes de la lectura, se recomienda plantear propósitos, objetivos o intenciones.

- Durante el proceso de comprensión, el lector asume un rol activo, por lo tanto, necesita encontrarle sentido al esfuerzo cognitivo que realizará.

- La motivación, recreada por los docentes, debe estar presente durante toda la lectura.

- El texto debe tener una estructura lógica y ser coherente.

Los conocimientos previos que tiene un lector acerca del tema del texto le servirá para que mejore su comprensión y reorganice su conocimiento elaborando su esquema de conocimiento (Coll, 1983 citado en Solé, 1999).

Sánchez, Orrantia y Rosales (1992) explican que las personas con pobre comprensión tienen deficiencias en el empleo de la progresión temática del texto, solo usan la estrategia del listado, así como solo la de suprimir y copiar y presentan deficiencias en la supervisión de la comprensión y en las estrategias de autorregulación. Por otro lado, los mismos autores mencionan que un lector con buena comprensión utiliza la progresión temática del texto, las estrategias estructurales, las macrorreglas de integración, selección y generalización y aplica flexible y adecuadamente estrategias y procesos.

De acuerdo con Pérez (2006, p. 51), el acto de leer tiene niveles y va más allá de la decodificación de palabras y sumar el significado de las mismas, pues para comprender un texto se debe recuperar información, configurar una interpretación y reflexionar sobre su contenido y forma.

\subsubsection{Nivel de comprensión literal}

El nivel de comprensión literal sirve para que el lector reconozca y recuerde. Estas dos capacidades fundamentales permiten responder preguntas sobre el reconocimiento y recuerdo de ideas (principales o temáticas), detalles, localización, características de personajes, identificación de elementos y relaciones explícitas de causa-efecto. También puede considerarse en este nivel la reorganización de la información, siempre y cuando esté explícita.

\subsubsection{Nivel de comprensión inferencial}

El nivel de comprensión inferencial implica que el lector una al texto sus hipótesis o conjeturas, producto de su conocimiento del mundo u otras lecturas. Este nivel permite añadir detalles que no están presentes en el texto, identificar el tema, el 
propósito del texto, deducir los significados de palabras o el sentido de expresiones que no estén definidas explícitamente, distinguir las características de un personaje que no se expresen literalmente en el texto.

Este nivel también se denomina interpretación. En las evaluaciones docentes, se utiliza el término infiere para el logro de este nivel. En este nivel se reorganiza la información, es decir, se ordenan las ideas utilizando procesos de clasificación y síntesis: clasificación de personas, objetos y lugares, elaboración de bosquejos de la estructura del texto y resumen de este texto.

Por otro lado, Cisneros, Olave y Rojas (2010) citan a Martínez (2002, p. 154) para clasificar las inferencias en enunciativas, léxicas, referenciales, macroestructurales, lógicas y argumentativas.

\subsubsection{Nivel de comprensión crítica}

El nivel de comprensión crítico-valorativo se refiere a la opinión o juicio de valor sobre distintos aspectos del texto. En la propuesta del Ministerio de Educación, en sus evaluaciones docentes, se basan en la opinión del contenido y los aspectos formales del texto. Este nivel tiene correspondencia con la capacidad denominada reflexiona en las mencionadas evaluaciones.

Para reflexionar $\mathrm{u}$ opinar sobre el contenido del texto, es necesario relacionar la información leída con los saberes del lector, provenientes de la lectura de otros textos o de su conocimiento del mundo.

\subsection{El texto expositivo}

Álvarez (2001) opta por emplear la denominación texto expositivo-explicativo debido a que en este tipo de texto frecuentemente se relacionan la intención de exponer y explicar.

- Exposición: pretende presentar una serie de datos e información.

- Explicación: persigue facilitar la comprensión más que solamente brindar información.

Para Álvarez (2001), el texto expositivo-explicativo es aquel cuyo objetivo primordial es expresar ideas para mostrarlas o hacerlas más comprensibles.

Los textos expositivos son importantes en el ámbito social y académico. Los estudiantes frecuentemente interactúan con este tipo de texto (por ejemplo, boletines, exposiciones, monografías, etc.). Asimismo, su relevancia se basa en el propósito de informar, generar nuevo conocimiento o modificarlo. Por lo mencionado, el 


\section{Jeancarlo Joel García Guadalupe}

texto expositivo debe ser empleado de forma intensiva en los colegios para que los alumnos dominen la comprensión y producción.

\subsubsection{Características del texto expositivo}

Según Slater y Graves (1990), hay cuatro características que definen el texto expositivo:

- Carácter informativo: Presenta información organizada sobre teorías, predicciones, personajes, hechos, fechas, especificaciones, limitaciones y conclusiones en una estructura conformada por párrafos.

- Connotación explicativa: Incorpora elaboraciones textuales relacionadas con las teorías, predicciones, personajes o hechos que desarrolla.

- Carácter directivo: Guía al lector presentando claves explícitas que le facilitan su comprensión lectora y la selección de ideas principales. El autor establece comunicación directa con el lector por medio de la cual relata, muestra y orienta la lectura y su comprensión textual.

- Contiene elementos narrativos que dan vida a la prosa. Las anécdotas, fábulas o cuentos en ri quecen la dinámica textual e ilustran determinados temas.

\subsubsection{Estructura del texto expositivo}

Kintsch (1982) citado en Álvarez (2005) afirma que en el tipo de texto expositivo hay formas o subtipos de organización debido a que los textos expositivos no se ciñen a una superestructura homogénea.

a. Descripción y definición. Está relacionada con conceptos como estructura, morfología, procedimiento, proceso, mecanismo, sistema, comparación, fases, etc.

b. Comparación y contraste (semejanzas y diferencias).

c. Problema-solución (pregunta-respuesta).

d. Causa consecuencia. Para exponer admite variaciones, de acuerdo a cómo se ordenen anterior o posteriormente los a n tecedentes y el consecuente.

e. La ilustración mediante mapas, tablas, fotografías, dibujos, esquemas, etc. Es otra de las representaciones o subtipos de organización de la información.

52 Lengua \& Sociedad, vol. 18, n. ${ }^{\circ}$ 1, Lima, enero-junio de 2019 
El uso de las macrorreglas en la comprensión lectora de textos expositivos

Gónzález y Marcilla (1996, citando a Meyer, 1984) y Viero, Peralbo y García (1997) afirman que los esquemas sirven en los procesos de comprensión y por ello exponen cinco esquemas retóricos que se encuentran en los textos expositivos:

- Texto expositivo de carácter descriptivo: da información de un tema particular, agrupa los rasgos, atributos o características de un tema, acontecimiento, o situación. No presenta palabras clave que ayuden a comprenderlo.

- Texto expositivo de carácter agrupador o colección: agrupa temas diversos en forma simultánea y sucesiva sin implicar un orden jerárquico, pero relacionándolos entre sí. Emplea palabras clave para enfatizar la continuidad como en primer lugar, a continuación, etc.

- Texto expositivo de carácter causal o causativo: organiza la información teniendo como eje dos categorías, la ascendente y la consecuente, y respeta la relación antes y después. Se emplean palabras clave a causa de, la razón por la que, por ende, de ahí que, etc.

- Texto expositivo de carácter aclaratorio o problema-solución: ordena la información en torno al planteamiento de un problema o situación problemática y sus posibles alternativas de solución. Se emplean las palabras clave una posible causa del problema, la pregunta que surge es y el problema consiste en, etc.

- Texto expositivo de carácter comparativo: hace referencia a dos o más fenómenos que se confrontan señalando sus semejanzas y diferencias.

Calfee y Curley (1984) presentan la siguiente clasificación de textos expositivos:

- Descriptivo. Presenta información al lector por medio de definiciones, divisiones clasificatorias o comparaciones.

- Ilustrativo. Expone al lector el contenido del texto estableciendo comparaciones entre hechos, ideas, personajes o conceptos. En algunos casos utiliza el ejemplo para ilustrar con mayor claridad un objeto o hecho.

- Secuencial. Por medio de sucesos o ejemplos interrelacionados explica al lector la estructura causa-efecto implícita en el texto. Ocasionalmente recurre a categorizaciones para complementar la explicación.

- Argumentativo. El autor del texto hace explícita su posición en la presentación del tema tratando de convencer al lector. Para ello utiliza argumentos de carácter inductivo o deductivo.

- Operacional. Presenta la secuencia de tres elementos: la introducción, que brinda una orientación general al lector sobre su contenido; la 


\section{Jeancarlo Joel García Guadalupe}

transición, que conecta la información existente y la nueva, y la conclusión, que permite sintetizar la información.

- Temporal. Expone una secuencia que refleja el paso del tiempo, o una progresión lógica entre los elementos que componen el texto.

De Rojo (1998) clasifica los textos expositivos según tengan trama narrativa o descriptiva. Los primeros desarrollan procesos históricos o naturales y presentan los hechos en una secuencia temporal o causal. Los segundos caracterizan objetos, personas o procesos por sus propios rasgos.

Por otro lado, se debe tener en cuenta que en los párrafos de los textos expositivos se puede encontrar las siguientes estructuras:

- Analizante o deductiva. La acción principal, la idea principal o la tesis va al inicio y, tras ella, se desarrollan los hechos, datos o argumentos en el resto del párrafo.

- Sintetizante o inductiva. La acción principal, la idea principal o la tesis se muestra al final. Se deriva o deduce de lo escrito anteriormente.

- Encuadrada. Lo importante se muestra al inicio y se vuelve a enunciar de manera reforzada al final del párrafo.

- Paralela. Toda la información tiene el mismo nivel de importancia. Se tiene que inferir la idea temática o acción importante.

- Concéntrica. La acción principal, la idea principal o la tesis se halla en el centro y en torno a ella gira la narración, exposición o argumentación.

\subsubsection{Marcas lingüísticas y textuales del texto expositivo}

De acuerdo con Álvarez y Ramírez (2010), las marcas textuales y lingüísticas más regulares en los textos expositivos son:

- Organizadores textuales. Representados por elementos paratextuales (tipo de letra, márgenes, títulos, subrayados, epígrafes, signos de puntuación, gráficos, esquemas) o frases: citas textuales, como dijimos anteriormente, como se explicará más adelante.

- Reformulaciones. Se realiza el parafraseo empleando expresiones como: dicho de otra manera, o sea, esto es, es decir, en otras palabras, etc. Además, se puede utilizar fórmulas para expresar ejemplos.

- Uso de aposiciones explicativas.

- Orden estable de palabras. Uso de la estructura sintáctica sujeto-verbocomplementos.

54 Lengua \& Sociedad, vol. 18, n. ${ }^{\circ}$ 1, Lima, enero-junio de 2019 
El uso de las macrorreglas en la comprensión lectora de textos expositivos

- Precisión léxica. Se emplean préstamos y extranjerismos, así como tecnicismos propios del lenguaje científico. En ese sentido, hay poco uso de valores estilísticos y pocos matices variados debido a que se pretende la universalidad y objetividad propias de los textos expositivos.

- Modalizadores o marcas de modalización. Presentan la opinión o la postura del autor. Hay empleo frecuente de modalizadores asertivos, es decir, los que plantean si un enunciado es verdadero o falso.

- Uso endofórico de los deícticos. Son marcas de cohesión textual que hacen alusión a elementos dentro del texto (anáforas y catáforas) y ayudan al lector a ubicarse en el texto. Hay expresiones anafóricas como lo dicho anteriormente o como ya se dijo. Asimismo, se utilizan expresiones catafóricas como más adelante diremos, a continuación señalamos, véase en el siguiente, etc.

- Uso frecuente de conectores de adición (por ejemplo, $y, e$ ), continuación, enumeración (en primer lugar, en segundo lugar, por ejemplo), causa (porque, debido a que, dado que), consecuencia (por lo tanto, por esa razón), comparación, ejemplificación (por ejemplo), explicación (es decir, en otras palabras), aclaración, reformulación, fuente, marcador de cierre, conclusión y resumidor.

- Empleo del modo indicativo, específicamente de los tiempos presente y futuro. Abundan, además, los verbos estativos, así como el copulativo ser; también se emplean regularmente verboides o impersonales, propias de lenguaje científico-académico.

- Adjetivación específica, pospuesta y valorativa. Se particulariza el sustantivo, en otras palabras, se agrega al significado del sustantivo. Es común el empleo de términos en función de adjetivos y así tenemos sustantivos en función de adjetivo, que se encuentran en aposición especificativa.

- Usual empleo de conceptualizaciones, descripciones, citas, hipótesis e inferencias inductivas y deductivas.

- Empleo de fórmulas de cierre que se expresan gracias a una conclusión o un resumen. Ej.: después de la breve exposición ..., el presente ejemplo representa sintéticamente... 


\section{Jeancarlo Joel García Guadalupe}

\section{Metodología}

El enfoque es el cuantitativo porque se quiere elaborar un marco teórico cuyas premisas establezcan relaciones entre las variables abordadas y se midan las frecuencias obtenidas mediante la aplicación de cuestionarios y test. Se quiere generalizar los resultados utilizando la estadística inferencial mediante la adopción de este enfoque (Bernal, 2006). Esta investigación es explicativa o causal, que se constituye como el nivel más alto de las investigaciones no experimentales, debido a que se estudiaron las causas de los hechos y los fenómenos. Se basó en la prueba de hipótesis y se pretendió que las conclusiones conlleven la formulación o el contraste de principios científicos (Bernal, 2006).

El diseño es el transeccional correlacional-causal. Según Hernández, Fernández y Collado (2014), estos diseños evidencian relaciones entre variables en un tiempo único y es correlacional-causal porque establece relaciones de causa-efecto.

La población la integraron 190 alumnos del segundo grado de secundaria de la Institución Educativa N. ${ }^{\circ} 1190$ Felipe Huamán Poma de Ayala. La investigación examinó a todos los estudiantes que forman parte de la población porque lo considera más útil, por eso se desarrolló un censo todos ellos (Cantoni, 2009; Hernández, Fernández y Collado, 2014; García, Flores y Parihuamán, 2019). Además se consideró como criterio de inclusión la matrícula formalizada en el año 2018; y como criterio de exclusión, la asistencia a clases durante ese año (regular, con pocas inasistencias). Así, finalmente, se aplicaron los instrumentos a 180 estudiantes.

Se empleó la encuesta (Survey) para el uso de las macrorreglas y la prueba (Test) para la comprensión de textos expositivos. El uso de las macrorreglas se midió con un cuestionario (Questionnaire) y la comprensión de textos expositivos con una prueba de conocimientos (Test) con alternativa múltiple.

\section{Resultados}

Los resultados de la aplicación del cuestionario sobre el uso de macrorregla evidencia que el 5,0 \% no usa la macrorregla de supresión; el 46,7 \% utiliza la forma poco frecuente; el 45,o \% la emplea de forma frecuente; finalmente, el 3,3 \% la usa de forma muy frecuente. Estos datos permiten afirmar que la mayoría utiliza de forma poco frecuente esta macrorregla.

56 Lengua \& Sociedad, vol. 18, n. ${ }^{\circ}$ 1, Lima, enero-junio de 2019 
El 2,2 \% no usa la macrorregla de generalización; el 40 \% que la emplea con poca frecuencia; el $50 \%$ que la utiliza frecuentemente; finalmente, el 7,8 \% la usa de forma muy frecuente. Estos datos permiten sostener que la mayoría utiliza de forma muy frecuente esta macrorregla.

El 3,9 \% no utiliza la macrorregla de construcción; el 37,2 \% que la emplea de forma poco frecuente; el 47,2 \% la utiliza frecuentemente; finalmente, el 11,7 \% la usa de forma muy frecuente. Estos datos permiten enunciar que la mayoría utiliza de forma muy frecuente esta macrorregla.

El 2,2 \% no utiliza macrorreglas; el 47,2 \% tiene un uso poco frecuente; el 48,3\% las utiliza de manera frecuente; finalmente, el 2,2 \% las emplea de forma muy frecuente. Estos datos permiten afirmar que la mayoría utiliza frecuentemente las macrorreglas.

En cuanto a los resultados de la prueba de comprensión de textos expositivos, el 4,4 \% se ubica en el nivel Inicio; el 15,6 \% en Proceso; el 39,4 \% en Logro previsto y el 40,6 \% en Logro destacado. Estos datos permiten declarar que la mayoría presenta un valor de Logro destacado en el nivel literal.

El 2,2 \% se ubica en el nivel Inicio; el 18,9 \% en Proceso; el 49,4 \% en Logro previsto y el $29,4 \%$ en Logro destacado. Estos datos permiten sostener que la mayoría se ubica en Logro previsto en el nivel inferencial.

El 16,1 \% se ubica en el nivel Inicio; el 28,3 \% en Proceso; el 35,6 \% en Logro previsto y el $20 \%$ en Logro destacado. Estos datos permiten decir que la mayoría se ubica en Logro previsto en el nivel crítico.

Finalmente, el 13,9 \% se ubica en el nivel Inicio; el 29,4 \% en Proceso; el $45 \%$ en Logro previsto y el 11,7 \% en Logro destacado. Estos datos permiten manifestar que la mayoría se ubica en Logro previsto en la comprensión de textos expositivos.

En cuanto a las pruebas de hipótesis, la prueba de la hipótesis específica 1 afirma que el coeficiente de correlación $(\mathrm{R}=0.239)$ permite saber que hay relación débil. Asimismo, el coeficiente de determinación $(\mathrm{R}$ cuadrado $=0.057)$ demuestra un porcentaje de influencia de $5.7 \%$ y el restante $94.3 \%$ pertenece a otros factores propios del azar. El valor Sig. $0.001<0.01$ permite postular con un $99 \%$ de confianza que existe relación y dependencia entre ambas variables. Por eso se afirma que el uso de las macrorreglas repercute en el nivel de comprensión literal de textos expositivos ( $p<0.01 ; 5.7 \%$ de influencia; 0.239 que indica correlación débil).

En cuanto a las pruebas de hipótesis, la prueba de la hipótesis específica 2 afirma que el coeficiente de correlación $(\mathrm{R}=0.316)$ permite saber que hay relación débil. Asimismo, el coeficiente de determinación $(\mathrm{R}$ cuadrado $=0.100)$ demuestra un 


\section{Jeancarlo Joel García Guadalupe}

porcentaje de influencia de $10 \%$ y el restante $90 \%$ pertenece a otros factores propios del azar. El valor Sig. $0.000<0.01$ permite postular con un $99 \%$ de confianza que existe relación y dependencia entre ambas variables. Por eso se afirma que el uso de las macrorreglas repercute en el nivel de comprensión inferencial de textos expositivos ( $p<0.01 ; 10 \%$ de influencia; 0.316 que indica correlación débil).

En cuanto a las pruebas de hipótesis, la prueba de la hipótesis específica 3 afirma que el coeficiente de correlación $(\mathrm{R}=0.100)$ permite saber que hay relación débil. Asimismo, el coeficiente de determinación $(\mathrm{R}$ cuadrado $=0.010)$ demuestra un porcentaje de influencia de $1 \%$ y el restante $99 \%$ pertenece a otros factores propios del azar. El valor Sig. $0.000<0.01$ permite postular con un $99 \%$ de confianza que hay relación y dependencia entre ambas variables. Por lo tanto, se afirma que el uso de las macrorreglas repercute en el nivel de comprensión crítica de textos expositivos ( $p<0.01 ; 1 \%$ de influencia; 0.100 que indica correlación débil).

Finalmente, la prueba de la hipótesis general sustenta que el coeficiente de correlación $(\mathrm{R}=0.317)$ permite saber que hay relación débil. Asimismo, el coeficiente de determinación $(\mathrm{R}$ cuadrado $=0.101$ ) demuestra un porcentaje de influencia de $10,1 \%$ y el restante $89,9 \%$ pertenece a otros factores propios del azar. El valor Sig. $0.000<0.01$ permite postular con un $99 \%$ de confianza que hay relación y dependencia entre ambas variables. Entonces, se establece que el uso de las macrorreglas repercute en la comprensión de textos expositivos de los estudiantes del segundo grado de secundaria de la Institución Educativa $1190(p<0.01 ; 10,1 \%$ de influencia; 0.317 que indica correlación débil) (apéndice H).

\section{Discusión}

Los resultados muestran que el uso de las macrorreglas repercute en el nivel de comprensión literal de textos expositivos en estudiantes de segundo grado de secundaria $(\mathrm{p}<0.01)$, con un $5,7 \%$ de influencia y una correlación débil $(\mathrm{r}=0.239)$. En esa misma línea, Alva, Castrejón y Pérez (2007), en su investigación en alumnos de tercer grado de secundaria, concluyeron que la aplicación de macrorreglas logra resultados positivos en la comprensión literal de textos narrativos, porque en el grupo experimental se obtuvo un porcentaje más alto $(91,4 \%)$ con resultados buenos, en contraste con el grupo control que logró un porcentaje elevado (48,6 \%) con resultados regulares. También Málaga (2013) expone que la aplicación de las macrorreglas mejoró el nivel literal de la comprensión de textos narrativos en alumnos de segundo de secundaria, ya que el promedio del grupo 
experimental en el pretest fue de 11.7 y en el postest, de 13.83. Asimismo, Vela (2017) propone una macrorregla de adición y afirma que su aplicación obtuvo mejores promedios $(2,65)$ y porcentajes $(69,9 \%$ en logro previsto) en el grupo experimental, en contraste con el grupo control, con promedios $(1,82)$ y porcentajes inferiores $(\mathrm{p}<0.01)$. Se puede manifestar entonces que hay estudios experimentales que afirman la utilidad de las macroestrategias en la comprensión de diferentes tipos de textos.

También se encontraron resultados similares en estudios correlacionales, por ejemplo entre el uso de macrorreglas y el nivel de comprensión literal. Así, Martín (2013) expresa que este nivel tiene relación con inferencias, valoración, síntesis y subrayado (se incluyen conceptualmente en las macroestrategias), y la diferencia de medias se aprecia mejor en el grupo experimental $(3,69)$, en contraste con el grupo control $(2,77)(\mathrm{p}<0,01)$. Estos resultados eran de esperarse, dada la naturaleza literal de la macrorregla de supresión, que permite tener un mapa o saber la ubicación de la información requerida por una pregunta para contestarla de manera acertada.

En cuanto a los resultados de estadística descriptiva de esta investigación, el nivel de comprensión literal de textos expositivos está en su mayoría en el nivel Logro previsto (48,3\%) o Logro destacado (40,6 \%); entonces se puede interpretar que la mayor parte de los alumnos puede ubicar o localizar información en textos expositivos complejos, es decir, textos con secuencias o bases (Werlich; 1975 y Adam; 1992; 2005) instructivas, descriptivas, narrativas, transaccionales o argumentativas, pero en los que predomina la secuencia o base informativa-expositiva.

Además, el uso de las macrorreglas repercute en el nivel de comprensión inferencial de textos expositivos $(\mathrm{p}<0.01)$, con un $10 \%$ de influencia con correlación débil $(\mathrm{r}=0.316)$. Análogamente, Alva, Castrejón y Pérez (2007) explicaron que la aplicación de macrorreglas tiene resultados buenos en la comprensión inferencial de textos narrativos en tercer grado de secundaria, porque en el grupo experimental se obtuvo un porcentaje más alto $(48,6 \%)$ con resultados regulares, en contraste con el grupo control que tuvo un porcentaje elevado $(94,2 \%)$ con resultados deficientes. También Málaga (2013) señala que la aplicación de las macrorreglas mejoró el nivel inferencial de la comprensión de textos narrativos, debido a que el promedio del grupo experimental en el pretest es de $9.63 \mathrm{y}$ en el postest de 13.93 .

Asimismo, en investigaciones correlacionales entre el uso de macrorreglas y la comprensión de nivel inferencial, Martín (2013) expone que este nivel tiene 


\section{Jeancarlo Joel García Guadalupe}

relación con el vocabulario, síntesis, subrayado, valoración, comprensión literal y en la diferencia de medias se muestra una mejora en el grupo experimental $(1,59)$, en contraste con el grupo control $(1,06)(\mathrm{p}<0,01)$.

En cuanto a los resultados de estadística descriptiva de esta investigación, el nivel de comprensión inferencial de textos expositivos está en su mayoría en el nivel Logro previsto $(49,4 \%)$ o Logro destacado $(29,4 \%)$, es decir, la mayor parte de los alumnos del segundo grado puede deducir relaciones lógicas (causales, de finalidad y de problema-solución), el tema, las ideas principales y temáticas, el tipo de texto, el tono del texto, el propósito del texto, el significado de palabras o frases con sentido figurado y elaborar conclusiones.

También se afirma que el uso de las macrorreglas repercute en el nivel de comprensión crítica de textos expositivos $(\mathrm{p}<0.01)$, con un $1 \%$ de influencia con correlación débil $(\mathrm{r}=0.100)$. Análogamente, Alva, Castrejón y Pérez (2007) demostraron que la aplicación de macrorreglas tiene resultados buenos en la comprensión crítica de textos narrativos en alumnos de tercer grado de secundaria, porque en el grupo experimental se obtuvo un porcentaje más alto $(57,1 \%)$ con resultados buenos, en contraste con el grupo control que logró un porcentaje elevado (82,9\%) con resultados deficientes. Además, Málaga (2013) considera que la aplicación de las macrorreglas mejoró el nivel crítico de la comprensión de textos narrativos, puesto que el promedio del grupo experimental en el pretest es de 9.03 y en el postest de 11.77. Es aconsejable plantear estrategias para desarrollar y mejorar los niveles de comprensión crítica-valorativa, puesto que las macroestrategias no repercuten en este nivel. Esta sugerencia se basa en los puntajes bajos del nivel crítico de comprensión de textos en comparación con los niveles literal e inferencial. Por ello se recomienda adaptar las actividades del uso de las macrorreglas y usar otros marcos teóricos para obtener logros significativos.

También se encontraron resultados similares en estudios correlacionales, por ejemplo entre el uso de macrorreglas y el nivel de comprensión crítica (llamado también valoración). Martín (2013) sustenta que este nivel tiene relación con el vocabulario y las inferencias, y en la diferencia de medias se muestra una mejora en el grupo experimental $(1,19)$, a diferencia del grupo control $(0,97)(\mathrm{p}<0,05)$.

En cuanto a los resultados de estadística descriptiva de esta investigación, el nivel de comprensión crítica de textos expositivos está en su mayoría en el nivel En proceso (28,3\%) o Logro previsto (35,6 \%); esto evidencia que los alumnos del segundo grado pueden explicar, con dificultades, la intención del autor con respecto al uso de los recursos formales, la función de porciones del texto al 
sentido global, identificar la relación entre una afirmación externa al texto y una idea del texto, opinar sobre el contenido textual y emplear ideas del texto para sustentar opiniones de terceros.

El uso de las macrorreglas repercute en la comprensión de textos expositivos de los estudiantes del segundo grado de secundaria $(\mathrm{p}<0.01)$, con 10,1\% de influencia y con correlación débil $(r=0.317)$. En otro contexto, García (2014), en un estudio en alumnos de cuarto de primaria, reporta que el grupo experimental a nivel de postest logró como promedio 8,70 , en contraste con el grupo control que obtuvo 8,68. Si bien la diferencia no es significativa, muestra la eficacia de las macrorreglas o macroestrategias. En resultados de investigaciones similares que abordan otros tipos textuales, se puede mencionar el de Alva, Castrejón y Pérez (2007), debido a que, en su investigación en estudiantes de tercer grado de secundaria, la aplicación de macrorreglas en la comprensión de textos narrativos logró resultados buenos, porque en el postest el promedio del grupo experimental (16), con un gran porcentaje $(71,4 \%)$ en resultados buenos, es superior al grupo control $(7,5)$, con un mayor porcentaje $(82,9 \%)$ en resultados deficientes $(\mathrm{p}<0.05)$.

Asimismo, las macrorreglas mejoran la comprensión lectora según Vela (2017), esto se sustenta en sus resultados según los cuales el grupo experimental logró mejores promedios $(2,65)$, en contraste con el grupo control, con promedios $(1,82)$ inferiores $(\mathrm{p}<0.01)$. Además, Málaga $(2013)$ investiga la repercusión de las macrorreglas en la mejora de los niveles de comprensión de textos narrativos en estudiantes de segundo grado de secundaria y señala que el promedio del grupo experimental en el pretest es de 9.94 y en el postest de 13.18. Los resultados de la aplicación de las macrorreglas demuestran eficacia en otros contextos, como el caso de Pallares (2016), quien concluye que el modelo de Van Dijk, que abarca categorías como la macroestructura, las microestructuras y las macrorreglas, repercute en la comprensión lectora en el noveno grado $(\mathrm{p}<\mathrm{o}, 01)$.

En cuanto a los resultados de estadística descriptiva de esta investigación, el nivel de comprensión de textos expositivos está en su mayoría en el nivel En proceso $(29,4 \%)$ o Logro previsto (45\%). Estos resultados se pueden comparar con los de Martín (2013), quien sustenta que la comprensión de textos expositivos muestra una mejora en el grupo experimental $(6,98)$, en contraste con el grupo control $(5,06)$.

El nivel del uso de macrorreglas está en su mayoría en Uso poco frecuente $(47,2 \%)$ o Uso frecuente ( $48,3 \%)$. Esto indica que los alumnos del segundo grado emplean regularmente actividades de supresión, selección, generalización o construcción 


\section{Jeancarlo Joel García Guadalupe}

en la lectura de textos. Es relevante este resultado ya que, como señalan Guerra y Martín (1992), las macrorreglas son primordiales en los procesos de comprensión y producción de textos, debido a que tienen bases en la psicolingüística, la lingüística textual y el enfoque comunicativo. Asimismo es factible su aplicación en programas (software) de procesadores de textos. Esta posibilidad de resumir textos gracias a programas es una realidad e incluso puede usarse en los celulares con aplicaciones (apps) como Resoomer, Herramienta Autorresumen de Microsoft Word, Linguakit, smmry, Tío conejo, Free Summarizer, o AutoSummarizer son ejemplos de aplicaciones de macroestrategias.

El nivel del uso de la macrorregla de supresión está en su mayoría en Uso poco frecuente $(46,7 \%)$ o Uso frecuente $(45 \%)$. Este resultado se compara con el de Atencio (2014), debido a que, en su aplicación en textos narrativos en alumnos del mismo grado, el 38,3\% reportó notas entre 11 y 13, lo que sugiere que esta macrorregla es mal empleada y sería recomendable orientar su uso adecuado.

Sobre el uso de la macrorregla de generalización, los alumnos de segundo grado de secundaria en su mayoría se ubican en el nivel de Uso poco frecuente (40 \%) o Uso frecuente (50\%). Este resultado se compara con el de Atencio (2014) debido a que, en su aplicación en textos narrativos en alumnos de segundo grado, el 41,2 \% reportó notas entre 14 y 17, lo que indica que no es empleada adecuadamente, de forma secuencial ni en tiempos establecidos para el desarrollo de una prueba.

Acerca del uso de la macrorregla de construcción, los estudiantes de segundo grado de secundaria en su mayoría se ubican en el nivel de Uso poco frecuente $(37,2 \%)$ o Uso frecuente (47,2 \%). Este resultado se compara con el de Atencio (2014), ya que, en su aplicación en textos narrativos en alumnos de segundo grado, el 49,7 \% obtuvo notas entre o y 10, lo que evidencia que su utilización no es adecuada: no muy empleada o no se usa de forma correcta. Entonces queda como una línea de investigación desarrollar el uso de esta macrorregla en distintos tipos de texto y en distintos niveles, para ver sus posibilidades de aporte en la identificación de las macroestructuras textuales.

\section{Conclusiones}

a. El uso de las macrorreglas repercute en la comprensión de textos expositivos de los estudiantes del segundo grado de secundaria de la Institución Educativa N. ${ }^{\circ} 1190$ Felipe Huamán Poma de Ayala de Chosica, $2018(\mathrm{p}<0.01 ; \mathrm{r}=0.317$; influencia de 10,1\%). 
El uso de las macrorreglas en la comprensión lectora de textos expositivos

b. El uso de las macrorreglas repercute en el nivel de comprensión literal de textos expositivos ( $\mathrm{p}<0.01 ; \mathrm{r}=0.239$; influencia de $5,7 \%)$.

c. El uso de las macrorreglas repercute en el nivel de comprensión inferencial de textos expositivos ( $<$ o.o1; $r=0.316$; influencia de $10 \%)$.

d. El uso de las macrorreglas repercute en el nivel de comprensión crítica de textos expositivos ( $\mathrm{p}<0.01 ; \mathrm{r}=0.100$; influencia de $1 \%)$.

e. Se concluye que se debe seguir la adaptación de las macrorreglas a los diferentes tipos de textos y contribuir teóricamente al análisis del discurso o a la lingüística textual. Esta adecuación posibilitaría seguir obteniendo buenos puntajes en las pruebas de comprensión lectora nacionales e internacionales. Además se deben adaptar las macroestrategias a los formatos textuales discontinuos, debido a que, por carecer de párrafos, imposibilita el empleo total de los pasos de la supresión, selección, generalización y construcción de información del texto.

\section{Referencias bibliográficas}

Adam, J. (1992). Les textes: types et prototypes. Récit, description, argumentation, explication et dialogue. París: Nathan.

Adam, J. (2005). La linguistique textuelle. Introductionà l'analyse textuelle des discours. Paris: Armand-Colin.

Alexopoulou, A. (2011). Tipología textual y comprensión lectora en E/LE. Revista Nebrija de Lingüística Aplicada, 9. Recuperado de: https://www.nebrija.com/ revista-linguistica/files/articulospdf/articulo_530b646902516.pdf

Alliende, F., \& Condemarín, M. (1998). La lectura: teoría, evaluación y desarrollo. Santiago: Andrés Bello.

Alva, G.; Castrejón, L., \& Pérez, L. (2007). Aplicación de macrorreglas para mejorar la capacidad de comprensión de textos narrativos en los alumnos del $3 .^{\text {er }}$ grado de Educación Secundaria de la I. E. «Gustavo Ríes» de la ciudad de Trujillo en el año 2007 (Tesis de licenciatura). Instituto Superior Pedagógico Público Indoamérica, Trujillo. Recuperado de: https://es.scribd.com/doc/46326958/ aplicacion-de-macrorreglas-para-mejorar-la-comprension-de-textos-narrativos

Álvarez, T. (2001). Textos expositivo-explicativos y argumentativos. Barcelona: Octaedro.

Álvarez, T. (2005). Didáctica del texto en la formación del profesorado. Madrid: Síntesis. 


\section{Jeancarlo Joel García Guadalupe}

Araoz, E.; Guerrero, P.; Villaseñor, R., \& Galindo, M. (2008). Estrategias para aprender a aprender. Reconstrucción del conocimiento a partir de la lectoescritura. México: Pearson.

Atencio, C. (2014). Nivel de uso de las macrorreglas textuales en la comprensión de textos narrativos en los estudiantes del $2^{\circ}$ grado de la I. E. S. Independencia Nacional-Puno en el año 2014 (Tesis de licenciatura). Universidad Nacional del Altiplano, Puno. Recuperado de: http://repositorio.unap.edu.pe/bitstream/handle/unap/8602/atencio_mendoza_claudia_maria_ricardina. pdf? sequence $=1$ \&isallowed $=\mathrm{y}$

Bernal, C. (2006). Metodología de la investigación para administración, economía, humanidades y ciencias sociales. México: Pearson.

Calfee, R. C., \& Curley, R. (1984). Structure of prose in the content areas. En J. Flood (ed.), Understanding reading comprehension. Newark: IRA.

Cisneros, M.; Olave, G., \& Rojas, I. (2010). La inferencia en la comprensión lectora. De la teoría a la práctica en la Educación Superior. Pereira: Universidad Tecnológica de Pereira.

Díaz-Barriga, F. y Hernández, G. (2003). Estrategias docentes para un aprendizaje significativo. Una interpretación constructivista. México: McGraw-Hill.

García, A. (2014). Enseñanza de la estrategia de macrorreglas para mejorar la comprensión lectora de textos expositivos en alumnos de $4^{\circ}$ de primaria (Tesis de licenciatura). México: Universidad Pedagógica Nacional. Recuperado de: http://200.23.113.51/pdf/30908.pdf

García, J. J.; Flores, R. y Parihuamán, G. (2019). Herramientas informáticas para elaborar proyectos de tesis. Lima: Camaleón Publicidad e Impresiones.

Golder, C. y Gaonacíh, D. (2002). Leer y comprender: psicología de la lectura. México: Siglo XxI.

Golder, C. y Gaonacíh, D. (2005). Manual de psicología para la enseñanza. México: Siglo Xxi.

Guerra, L. y Martín, J. (1992). Informática aplicada a la comprensión textual. Comunicación, Lenguaje y Educación 13, pp. 95-101. Recuperado de: https:// dialnet.unirioja.es/descarga/articulo/126241.pdf

Hernández, R.; Baptista, P. y Fernández, C. (2014). Metodología de la investigación. (6. ${ }^{\text {ta }}$ ed.). México: Mc Graw-Hill.

Kintsch, W. (1982). Aspects of text comprehension. En Le-Ny y W. Kintsch (eds.) Language and comprehension, Amsterdam: North-Holland, pp. 301-312.

64 Lengua \& Sociedad, vol. 18, n. ${ }^{\circ}$ 1, Lima, enero-junio de 2019 
El uso de las macrorreglas en la comprensión lectora de textos expositivos

Málaga, C. y Mendoza, Y. (2013). Aplicación de macrorreglas para mejorar los niveles de comprensión de textos narrativos en estudiantes del $2^{\circ}$ grado de la I.E.S. Comercial N. ${ }^{\circ} 45$ «Emilio Romero Padilla»-Puno en el año 2011 (Tesis de licenciatura). Puno, Universidad Nacional del Altiplano. Recuperado de: http:// repositorio.unap.edu.pe/bitstream/handle/unap/8320/m\%c3\%a1laga_apaza_ carol_lissbet_mendoza_alcca_yadmina_rossini.pdf? sequence $=1$ \&isallowed $=\mathrm{y}$ Martín, J. (2013). La comprensión de textos expositivos en el aula de Ciencias Sociales en la Educación Secundaria (Tesis doctoral). Granada: Universidad de Granada. Recuperado de: https://hera.ugr.es/tesisugr/22705557.pdf

Martínez, M. (2002). Lectura y escritura de textos. Perspectivas teóricas y talleres. Cali: Universidad del Valle.

Meyer, B. J. F. (1984). Text dimensions and cognitive processing. En H. Mandl, M. L. Stein y T. Trabaos (eds.), Learning and comprehension of text. New York: Lawrence Erlbaum Associates.

Ministerio de Educación (2013). Comprensión y producción de textos escritos VII Ciclo. Lima: Navarrete.

Ministerio de Educación (2014). Módulo de comprensión lectora 1. Lima: Quad Graphics.

Ministerio de Educación (2015). Módulo de comprensión lectora 1 (2. ${ }^{\mathrm{da}}$ ed.). Lima: Quad Graphics.

Ministerio de Educación (2016a). ¿Qué logran nuestros estudiantes en Lectura? Evaluación Censar de Estudiantes 2015. Informe para docentes 2. ${ }^{\circ}$ grado de Secundaria. Unidad de Medición de la Calidad de los Aprendizajes: Lima.

Ministerio de Educación (2016b). Evaluación PISA 2015: primeros resultados. Unidad de Medición de la Calidad de los Aprendizajes: Lima. Recuperado de: http://umc.minedu.gob.pe/wp-content/uploads/2016/12/presentaci\%c3\%b3n-web-pisa-peru-1.pdf

Ministerio de Educación (2017a). ¿Qué logran nuestros estudiantes en Lectura? Evaluación Censal de Estudiantes 2016. Informe para docentes 2..$^{\circ}$ grado de Secundaria. Unidad de Medición de la Calidad de los Aprendizajes: Lima.

Ministerio de Educación (2017b). Marco de evaluación de la competencia lectora de PISA 2018. Unidad de Medición de la Calidad de los Aprendizajes: Lima.

Ministerio de Educación (2017c). El Perú en PISA 2015. Informe nacional de resultados. Lima: Oficina de Medición de la Calidad de los Aprendizajes. 


\section{Jeancarlo Joel García Guadalupe}

Ministerio de Educación (2019). ¿Qué logran nuestros estudiantes en Lectura? Evaluación Censar de Estudiantes 2018. Informe para docentes $2 .^{\circ}$ grado de Secundaria. Unidad de Medición de la Calidad de los Aprendizajes: Lima.

Pallares, I. (2016). El modelo propuesto por Van Dijk y Kintsch y la comprensión lectora de los estudiantes de noveno grado del Instituto Agrícola de Charta en el Municipio de Charta en el departamento de Santander-Colombia 2014 (Tesis de maestría). Lima, Universidad Norbert Wiener. Recuperado de: http:// repositorio.uwiener.edu.pe/bitstream/handle/123456789/596/maestro\%20-\%20 pallares\%20amaya $\% 2$ oirina $\%$ 2opatricia.pdf? sequence $=1$ \&isallowed $=y$

Rojo, M. de. (1998). El texto expositivo y su comprensión [Documento de Internet]. Recuperado de: http://www.valladolid.ed.mx/maristas/piensaplus/textexp.htm Sánchez, E.; Orrantia, \& Rosales. (1992). Cómo mejorar la comprensión de textos en el aula. Comunicación, Lenguaje y Educación, 14, 89-112.

Sánchez, E. (1993). Los textos expositivos. Estrategias para mejorar su comprensión. Madrid: Santillana.

Slater, W y Graves, M. (1990). Investigaciones sobre el texto expositivo: aportes para los docentes. En K. D. Muth (Ed.), El texto expositivo. Estrategias para su comprensión, Buenos Aires: Aique.

Solé, I. (1999). Estrategias de lectura. Barcelona: Grao.

Van Dijk, T. A. (1983 [1978]). La ciencia del texto. Un enfoque interdisciplinario. Barcelona: Paidós.

Van Dijk, T. A. y Kintsch, W. (1978). Cognitive psychology and discourse: Recalling and summmarizing stories. En W. Dressler (Ed.), Current Trends in Text Linguistics, pp. 61-80. Berlin: Mouton de Gruyter.

Van Dijk, T. A. y Kintsch, W. (1983). Strategies of Discourse Comprehension. Nueva York: Academic Press.

Vela, A. (2017). Macrorreglas de adición para mejorar la comprensión lectora en estudiantes de Educación Secundaria (Tesis doctoral). Tarapoto, Universidad César Vallejo. Recuperado de: http://repositorio.ucv.edu.pe/bitstream/handle/ ucv/16706/vela_ma.pdf? sequence $=1$ \&isallowed $=y$

Viero, I.; Peralbo, M. y García, M. (1997). Procesos de adquisición de la lectoescritura. Madrid: Visor.

Werlich, E. (1975). Typologie der Texte. Heidelberg: Quelle y Meyer. 